\title{
A Consumer-Centric Open Innovation Framework for Food and Packaging Manufacturing
}

\author{
Panagiotis Tsimiklis, Brunel University, London, UK \\ Fabrizio Ceschin, Brunel University, London, UK \\ Stephen Green, Brunel University, London, UK \\ Sheng Feng Qin, Northumbria University Newcastle, Newcastle upon Tyne, UK \\ Jim Song, Brunel University, London, UK \\ Sharon Baurley, Royal College of Art, London, UK \\ Tom Rodden, University of Nottingham, Nottingham, UK \\ Charalampos Makatsoris, Brunel University, London, UK
}

\begin{abstract}
Closed innovation approaches have been employed for many years in the food industry. But, this sector recently perceives its end-user to be wary of radically new products and changes in consumption patterns. However, new product development involves not only the product itself but also the entire manufacturing and distribution network. In this paper, we present a new ICT based framework that embraces open innovation to place customers in the product development loop but at the same time assesses and eventually coordinates the entire manufacturing and supply chain. The aim is to design new food products that consumers will buy and at the same time ensure that these products will reach the consumer in time and at adequate quantity. On the product development side, our framework enables new food products that offer an integrated sensory experience of food and packaging, which encompass customization, healthy eating, and sustainability.
\end{abstract}

Keywords: Consumer-CentricNewProductDevelopment, FoodandPackaging Manufacturing, Information and Communication Technology, Knowledge Driven Manufacturing, Open Innovation

DOI: $10.4018 /$ ijkss.2015070104 


\section{INTRODUCTION}

Two of the key challenges that face the food manufacturing industry include the ability to identify market segments that have different sensory needs, and the ability to respond quickly to these segments. Nowadays, new food products must offer an integrated sensory experience of food and packaging, which encompass customization, healthy eating, and sustainability. Although, one could argue that the food industry is an active industry, with roughly 3,500 new products reaching the UK retailer selves every year, at the same time, it suffers from massive Research and Development waste, as $80 \%$ of those new products are expected to fail within the initial two years since their launch onto the market and hence, they cannot provide a decent return on development investment (DEFRA, 2009). A key reason is that traditional New Product Development techniques do not obtain unbiased inputs from consumers who are not involved in the loop of those techniques (Miranda and Bañegil, 2002; Monsef et al., 2012.

By embracing Open Innovation models to interact with consumers at the place of product consumption, we can discover new market segments and understand their needs. Then, by integrating new product design, production and business systems in an ICT (Information \& Communication Technology) platform, food manufacturing networks can be established and enabled by rapidly configuring on-demand the structure of the network according to particular product line requirements. This integration will also allow the allocation of production demand dynamically responding rapidly, economically and sustainably to the needs of new market segments identified.

In this paper, we present such a framework for the capturing and integration of consumers' needs, with new product development and manufacturing into a seamless process. Simulation and optimization models can then be used to enable expert users to discover the manufacturing capacity of any available installation, configure manufacturing networks and processes, select appropriate suppliers and assess risks associated with particular process and network configuration decisions in responding to those new market segments. Embedded in the models will be sustainability considerations such that compliance with environmental as well as business strategy is attained.

\section{APPROACH/MODEL}

The food industry is a mature and slow-growing one and is typically very conservative with the level of investment in new technology (Monsef et al., 2012). At the same time, it is a very active industry constantly seeking to identify and address the needs of new market segments, although innovation is restricted to incremental improvements of existing products (Sarkar and Costa, 2008).

The traditional closed innovation has been used for many years within the food industry. But, this sector recently perceives its end-user to be wary of radically new products and changes in consumption patterns (Sarkar and Costa, 2008). Such perceived wariness, together with the restricted legal requirements related to food safety, transforms food industry's innovation process into a highly complex, time-consuming and risky "odyssey", and hence one not to be lightly undertaken.

However, these recent important changes in the nature of both food demand and supply, coupled with an ever-increasing level of competitiveness, and the high volatility of global markets caused by the global financial crisis, have rendered innovation not only an unavoidable corporate activity, but also one that is increasingly vital for overall profitability and survival (Sarkar and Costa, 2008; Bigliardi and Galati, 2012).

\subsection{Challenges of the Food Industry}

According to UK Cabinet Office (2008) and DEFRA (2009) the UK Food Industry contributes GBP 80Bn to the UK Economy and represents $7 \%$ of the UK's GDP. Furthermore, 
the Food Industry employs 3.5 million people in 196,000 enterprises of all sizes in the UK alone. But, the industry is facing the following key global challenges:

1. The International Financial Crisis (Trompenaars and Hampden, 2009);

2. Global population is expected to increase by $9.1 \mathrm{Bn}$ in 2050 (UK Cabinet Office, 2008; DEFRA, 2009);

3. Global resources (energy, water, land) are rapidly being used up (UK Cabinet Office, 2008; DEFRA, 2009);

4. The fact that in developed countries, the mean number of members of a family is getting less (http://unstats.un.org/unsd/ demographic/products/Worldswomen/ Executive\%20summary.htm, last accessed 29/05/2014);

5. The "single" consumers prefer ready-to-use products in individual formats (Nielsen Report, 2006);

6. The reluctance to embrace new technology leads to missing on potential added-value opportunities (Sarkar and Costa, 2008; Bigliardi and Galati, 2012);

7. The commodity products are typically low profit margins ones (Sarkar and Costa, 2008; Bigliardi and Galati, 2012);

8. Consumers of undeveloped countries cannot afford to buy huge format packs (Manalili et al., 2011; Karnani, http:// www.worldfinancialreview.com/?p=215, last accessed 29/05/2014);

9. The new international labelling system requirements for the primary packaging (Hawkes, 2004);

10. The necessity for a more flexible worldwide distribution (Christopher, 2005); and

11. The demand for new products to be sourced, produced and delivered by sustainable way (UK Cabinet Office, 2008; Keating et al., 2010).

However, within the next fifty years, the biggest challenge that the food industry is going to face is that it is expected to produce more food than that has been produced in the entire history of humanity to meet the global demand (Keating et al., 2010).

\subsection{Embracing Open Innovation Models}

Open Innovation is defined as the purposive use of knowledge that exists both inside and outside any organization. That mixture of knowledge can speed-up the time-to-market process, enrich the internal innovation environment and expand any company's market frontiers far beyond to new market segments (Bigliardi and Galati, 2012). Nowadays, Open Innovation has been commonly associated with fast-growing industries, like the information and communication technology sector or the pharmaceutical industry (Chesbrough, 2003; Chesbrough et al., 2006; Chesbrough, 2006). There is, however, increasing evidence that this concept may also prevail in more traditional and mature industries as the food industry (Morcillo, 2007; Sarkar and Costa, 2008; Bigliardi and Galati, 2012; http:// www.youtube.com/watch?v=6V1dWH4X9U0, last accessed 29/05/2014).

Although Open Innovation is one of the most debated topics in actual global literature (Morcillo, 2007; Trompenaars and Hampden, 2009; Monsef etal., 2012; http://www.youtube. $\mathrm{com} /$ watch? $\mathrm{v}=6 \mathrm{~V} 1 \mathrm{dWH} 4 \mathrm{X} 9 \mathrm{U} 0$, last accessed $29 / 05 / 2014$ ), the majority of the studies are broad and there are still many questions that have not been answered. One of them is the link between the corporate Open Innovation practices and the food industry manufacturing structure.

Open Innovation offers a new approach to involve consumers in the loop and enable the design and production of food products that are desired and will actually be consumed (Chesbrough, 2003; Chesbrough et al., 2006; Chesbrough, 2006). However, in contrast to the current application of Open Innovation which mainly relates to the closer engagement and involvement of suppliers in corporate R\&D, our Open Innovation model embraces crowdsourcing technology to place the end consumer in the New Product Development loop. This is 
a way to mobilise and obtain more fine grained perceptions from consumers in order to identify and define more precisely discrete market segments and as a results, we can accelerate New Product Design (NPD) and make the process more efficient within that mature industry (Miranda and Bañegil, 2002; Monsef et al., 2012).

To facilitate the achievement of the above objectives, a cross-functional team is often created. It is a rich picture of different actors working together in iterative processes of trial and error to bring the successful commercial exploitation of new idea (Tidd et al., 2000). That team might be restricted to employees within an organisation but, the ideal is to cross the boundaries and to include suppliers and other strategic partners (Laursen and Salter, 2006). Furthermore, issues related to knowledge management, empowerment and education have a significant interaction with teams, as companies strive to ensure that teams have the appropriate knowledge, skills and authority to accomplish their objectives within a dynamic business environment (Laursen and Salter, 2006).

Additionally, in the area of information technology, and production planning and control, special software systems are needed to enable teams to work together in a distributed or virtual environment. The role of networks, communities and linkages has come to the fore in investigations of innovative performance (Laursen and Salter, 2006).

An ICT implementation of the framework we propose will comprise digital media and information management tools that enable an integrated product experience encompassing:

- Customisation: Building and blending your own food;

- Being involved in food manufacture: Having 'conversations' with brands;

- Social aspects of eating and sharing: People congregate around shared affinities; gift giving; sharing knowledge;

- Nutrition and health: Supporting individual nutritional needs according to lifestyle and goals;
- Sustainable and ethical issues: Relating to food sourcing, packaging design.

In addition, we propose to integrate simulation and optimisation tools that will enable the re-configuration of manufacturing lines for responding to the needs of emerging market segments rapidly.

Those tools will support expert users to discover available manufacturing capacity within any installation and on that basis configure manufacturing networks and processes and select appropriate suppliers who can satisfy market demands highlighting the risks associated with particular process and network configuration decisions.

\subsection{The Framework}

Placing customers in the loop is a major change for most organisations that demands new thinking in developing and operations strategy. Operations Strategy is concerned with the choice of pattern of strategic decisions and actions which determine the role, objectives and activities of the organization (Wild, 1992; Christopher, 2005). There are the five basic performance objectives and they apply to all types of organisation:

1. Quality: Consistent conformance to customers' expectations;

2. Speed: The elapsed time between customers requesting products and their receiving them.

3. Dependability: Delivering or making available products when they were promised to the customer;

4. Flexibility: The quality of being adaptable or variable;

5. Cost: The amount paid.

Agile operations management aims at addressing those five performance objectives and is a central component to our framework. Agility is defined as the ability of a system to rapidly respond to change by adapting its initial 
configuration. It is the ability that combines and adopts any business system to any of all those 5 objectives (Christopher, 2000).

Agile Manufacturing (AM) is a companywide strategy that pursues to respond well to unexpected change in all aspects of a company's operations (Christopher, 2000). We can define it in two contexts:

- Externally: As perceived by customers: (AM) means responding to those customers' needs by rapidly designing and manufacturing products customized to those requirements;

- Internally: In terms of a company's own operations, (AM) focuses on reducing the lead times for all tasks in a company, resulting in improved quality, lower cost, and of course, quick response.
Figure 1 shows a scenario using Internet/ Intranet networks to speed up information flow in a product development cycle and thus to achieve reduced development time and costs.

Traditionally, however, efforts in the application of agile frameworks have been focused on shortages of traditional energy sources and their price fluctuations, the need for more energy - efficient products or products using alternative energy sources - is clear (Wild, 1992). Opportunities exist to re-engineer many industrial products based on new ratio of energy costs and capital costs. New energy - conservation concepts and service - will be needed. The design and marketing of this range of products are challenging because of price fluctuations.

Changes in energy availability and prices are but one example of the many possible futures we face. The many changes in the status quo

Figure 1. A scenario of using internet/intranet to support information flow in product development cycles

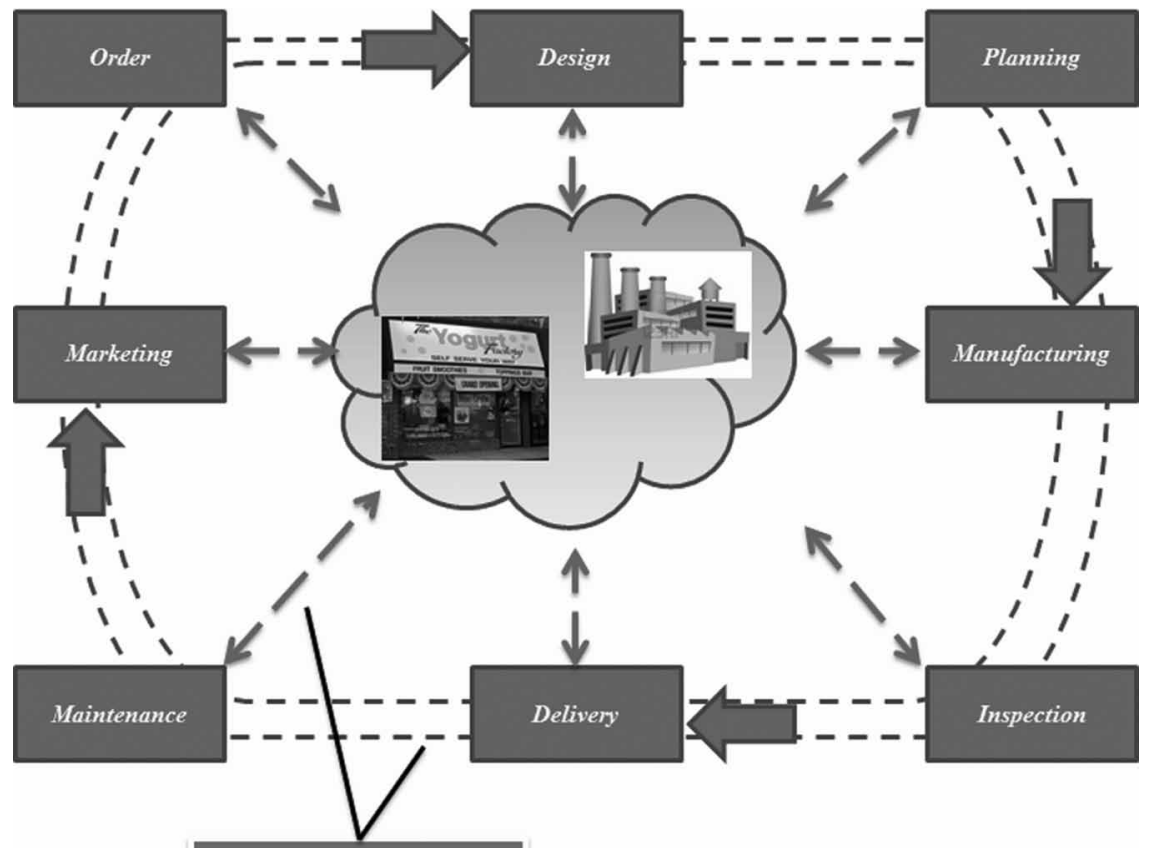

Internet/Intranet 
present problems for unchanging organisations but represent real opportunities for those organisations that adapt and evolve with new market offerings. The organisations that will not just survive but thrive will use a learning organisational concept with which will examine their role in society and our continuously changing environment. One of the important rationales for their existence is based on innovation and agility to fill societal and customer needs.

But, competition is also fierce today and businesses are under extreme pressure to innovate and to do so quickly and successfully. If innovation frameworks are too slow bringing a new product to market or they make mistakes along the way, businesses could be overtaken by faster moving competitors (Trompenaars and Hampden, 2009).

According to Lynn et al. (1999), the success of a new product is highly dependent on the next ten factors:

1. To have a structured new product development process;

2. To have a clear and shared vision on the team;

3. To develop and launch a product within the proper time frame;

4. To refine a product after launch and having a long-term view;

5. To possess the optimal team skills;

6. To understand the market and its dynamics;

7. To secure top management support for the team and the team's vision;

8. To apply lessons learned from past projects;

9. To secure good team chemistry; and

10. To retain team members with relevant experience.

However, for a team to develop a new product, two factors have been identified as the most important ones:

1. To know where it is going by having a clear vision; and

2. To follow a structured New Product Development process.
Additionally, to determine the impact of the previous mentioned ten factors on speed to market, the next results have been identified (Lynn et al., 1999):

1. The significance of Long Term View on Speed is probably attributable to the notion that if a company is planning for the long-term for a given product, and is not in it for a quick buck, the company will try to do its homework and gets the specs right the first time so that steps will not need to be repeated;

2. A well-defined New Product Development process can also help a company to reduce development time by giving to expert and multifunctional team members a framework within which to function - what should be done and when to do it.

Now, a typical New Product Development process can be divided into a fuzzy front end, product development and product launch (Chang et al., 2008). Although managers have realised the importance of new product development, most companies often end up with failure product outcome. The failure can be mostly attributed to the uncontrollability of new product ideas at a "go-kill" stage, leading to budget allocated to a product idea that will unlikely be successful (Chang et al., 2008). These uncontrollable factors include project delay, budget escalation and non-conformance to the market demands.

This is the reason why we think that it is really vital to place the customer in the product development loop as it entails the capturing and translation of external signals from the market into actionable information by the organization. But, how we can relate those external signals from the customers with the internal situation of a manufacturing organization?

In the era of open innovation, it is necessary a more active engagement of customers into new product development than traditional market research allows. To sustain the pace of innovation resulting from fast changing tech- 
nologies and customers' needs is suggested integrating customers into value creation and absorbing customers' knowledge to strengthen company's performance objectives and to discover their needs (Laursen and Salter, 2006). As a consequence, new methods are needed that allow active engagement of customers into New Product Development.

The Internet, for example, as an interactive and multimedia-rich technology with low costs of mass communication allows consumers to virtually experience new products and offers new ideas to the producers and designers. With its currently more than one billion users, the Internet offers an enormous pool of knowledge, impossible to encounter elsewhere. Users encountered in online communities present a promising source of innovation (Laursen and Salter, 2006; Garriga et al., 2013).

Now, it is our framework, in Figure 2, that has been designed to address this challenge. Our framework combines the UK Design Council's Double Diamond 4D design process and its steps of Discover, Define, Develop and Deliver (Design Council, 2005) with Chesbrough's Open Innovation Framework (Chesbrough, 2003; Chesbrough et al., 2006; Chesbrough, 2006).

Our framework comprises three information processing streams. The first stream is the Front End of the model, which comprises a crowdsourcing interface for harvesting attitudes/perceptions from consumers. It achieves that via a combination of both on-line and offline modes of interaction. By having in mind that one half of all local searches are performed on mobile devices and $60 \%$ of population sleep with their phones (Morcillo, 2007; Trompenaars and Hampden, 2009; http://www.youtube. $\mathrm{com} /$ watch? $\mathrm{v}=6 \mathrm{~V} 1 \mathrm{dWH} 4 \mathrm{X} 9 \mathrm{U} 0$, last accessed 29/05/2014), we can easily understand why the term crowdsourcing at that step is really more adequate. The term as itself describes a new web-based business model that harnesses the creative solutions of a distributed network of individuals through what amounts to an open call for proposals. In other words, a company posts

Figure 2. The relationship of open innovation with the double diamond $4 D$ design process model

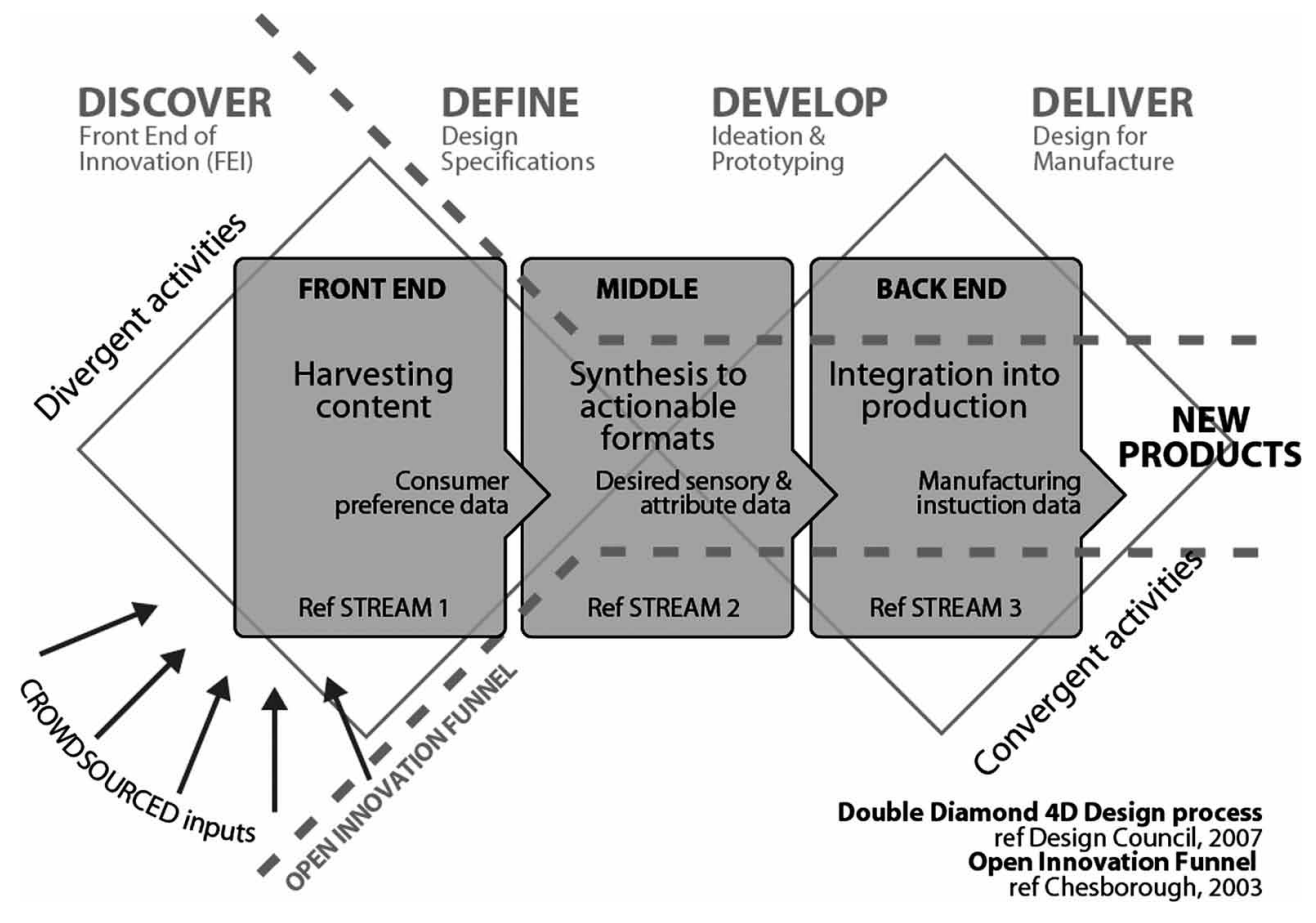

Copyright $(\mathcal{C}$ 2015, IGI Global. Copying or distributing in print or electronic forms without written permission of IGI Global is prohibited. 
or identifies a problem or a new idea online, a vast number of individuals offer solutions to that problem or idea, the winning solutions are awarded and developed and, finally, the company mass produces that idea for its own gain. It is therefore vital to use customers as source of ideas at this stage.

The second stream in the Middle is crucial for mapping the raw and usually very abstract inputs from consumers to actionable customer requirements. At this, stage, it is also crucial customers' participation as Co-creators and Testers. Engineering constraints and price impacts can be displayed in real-time while customer by using a web-based drag-and-drop option creates the latent product. This stream can also combine data visualization with machine learning techniques to achieve the previous mentioned and can provide specific design attributes for a new food product such as texture, rheology, viscosity, colour etc. from the sensorial preferences extracted from the crowds, to the Back End. This last stream is responsible for translating the consumer requirements into product specifications and ultimately determining the manufacturing and distribution instructions to satisfy the markets identified in a sustainable and economical manner. Simulation and optimization are crucial components of the Back End that are used to assess feasibility of manufacturing and supply and prepare plans to coordinate the entire supply chain.

\section{CASE STUDY AND DISCUSSION}

The presented framework for New Product Development workflow encompasses the "Open Innovation funnel" and the "Double Diamond 4D Design" design frameworks that have been mentioned above. This framework is intended for use by food companies who are seeking to use Open Innovation approaches in the product development loop during the design of new food products. The proposed framework is cross cutting as it extends beyond New Product Development by integrating processes designed to use that information to directly drive the development of new product recipes and subsequently drive product specification and ultimately production.

The Double Diamond 4D Design diagram was developed in 2005 by UK Design Council and describes the design process in a simple graphical way. That process is divided into four distinct phases: Discover, Define, Develop and Deliver, and it maps the divergent and convergent stages of the design process. By looking inside those four distinct phases, we can see the next:

1. Discover: This is the first stage of the model where the project starts. It begins with an initial idea or inspiration which is often sourced from a discovery phase in which user needs are identified. These include:
a. Market research;
b. User research;
c. Managing information;
d. Design research groups;

2. Define: It is the second stage and represents the definition part where interpretation and alignment of these needs to business objectives is achieved;

3. Develop: It is the development stage where design -led solutions are developed, iterated and tested within the company;

4. Deliver: It is the final stage where the resulting product is finalised and launched in the relevant market.

But, the research cost for the Discover stage of the previous process is very high (Henten, 2012) as well as the time needed to invest on such researches. In parallel, we have identified the Double Diamond 4D Design diagram as a discipline process to develop and bring new products to a relevant market (Design Council, 2005).

According to Monsef et al. (2012), a problem is that traditional NPD is risky due to alarming failure rates, and the large amounts of venture capital required. In investigating the reasons for the low success rates, stud- 
ies concluded that failed product innovators did not fully understand customer needs, designed products that cannot be repeatedly manufactured, and launched products without regard to the realities of those who will use the product (Dougherty, 1992).Open Innovation offers an approach to involve consumers in the loop of a New Product Development process and enable the design and production of food products that are desired and will be consumed (Chesbrough, 2003; Chesbrough et al., 2006; Chesbrough, 2006).

Thus, in this section, we present a case study concerned with the development and manufacture of yoghurt of a major manufacturer in Spain who employed approaches based on Open Innovation for new product development. The particularyoghurt products were developed jointly with regular and lead consumers who had been part of the process. The outcomes of the study where then used to drive process development by translating their requirements into actionable instructions to direct the design of the packaging, the product ingredient ratios and also the design and optimisation of the manufacturing line itself. Although the specific data cannot be presented due to confidentiality reasons, an overview of the study will be presented describing the procedures employed to harvest and synthesise the consumer inputs and illustrate their impact on manufacturing process design.

\subsection{New Innovation Models}

The central part of an innovation process involves the search for new ideas that have commercial potential. Thus, firms invest considerable amounts of time, money and other resources in the search for new innovative opportunities. Such investment increases the ability to create, use and recombine new and existing knowledge, external or internal knowledge available to a firm, or both (Laursen and Salter, 2006). All recent models of innovation have highlighted the interactive character of the innovation process, suggesting that the more innovative firms rely heavily on their interac- tion with users, suppliers and with a range of institutions inside the innovation system(Brown and Eisenhardt, 1995; Szulanski, 1996).

The Open Innovation Project the Dairy Company of this section conducted had precisely this aim: to identify and filter yoghurt product ideas that can be successfully brought to market as there is a clearly recognised and unmet need by a specific market segment. At the same time the project aimed at maximising the usage of existing resource as much as possible with minimal additional investment. One key risk is that the degree of product innovation/differentiation does not lead to increasing returns but rather remains stagnant no matter how big the investment is (Sarkar and Costa, 2008). The open innovation approach, at the core of our proposed framework, mitigated that risk by allowing the market to be a crucial component in the development loop of the new yoghurt product by directly influencing development priorities and at the same time maximising innovation impact.

\subsection{Harvesting Content}

As shown in Figure 3, it is a complex multidimensional project that requires many considerations and compromises to be made. A key target is to achieve sufficient differentiation compared to competition and this is embodied not only in the formulation of the product itself but also in the packaging, distribution and the design of the manufacturing and packaging processes themselves.

Initially, it is a "must" point to start such a kind of project by using the internal knowledge of the firm and to identify in a map where the actual business strategy of the firm is today and where it will need to be in the future when incorporating that new product (Slack et al., 2007).

Such an important value in an organization is the collaboration and communication across departmental and hierarchical boundaries. Selfdirected teams are the basics building blocks of the internal knowledge of a firm. These teams are made up of employees with different skills who share their experience and knowledge 
to produce an entire product. The idea is to empower the well-known "Cross-functional teams". That multi-functional expert group is normally formed by people from different functional departments such as Production, Marketing, Logistics, Finance, Engineering, Quality, $\mathrm{R}+\mathrm{D}$, Food Safety, Nutrition and Purchasing department but these people on the team must be given the skills, information, tools, motivation and authority to make decisions central to the team's performance and to respond creatively and flexibly to new challenges. Such a kind of team has been used to create the initial information needed to communicate initially with both customers and suppliers.

Then, a well-defined market investigation based on a qualitative research of concept, a quantitative research of product and a volumetric concept testing - on line or even next to the shops- can be used to indicate the appro- priateness of the idea (Sawhney and Prandelli, 2000). The main points to be covered on such researches should follow the considerations shown in Figure 3. Thus, those harvesting attitudes and perceptions from customers are then the important subjects to be investigated by our proposed model.

Hence, all that we propose is the integration of "the open innovation funnel" with the "double diamond" 4D design process described above. That is linked to the Front End of our model and we can propose some of them (Henten, 2012):

1. By creating different types of questionnaires focusing on customers' wants or "looking for" and posted on social web-sites (developed by a multifunctional team as described above);

2. By using specific "web questionnaires" posted on Intranets and asking firm's

Figure 3. Considerations for yoghurt product development

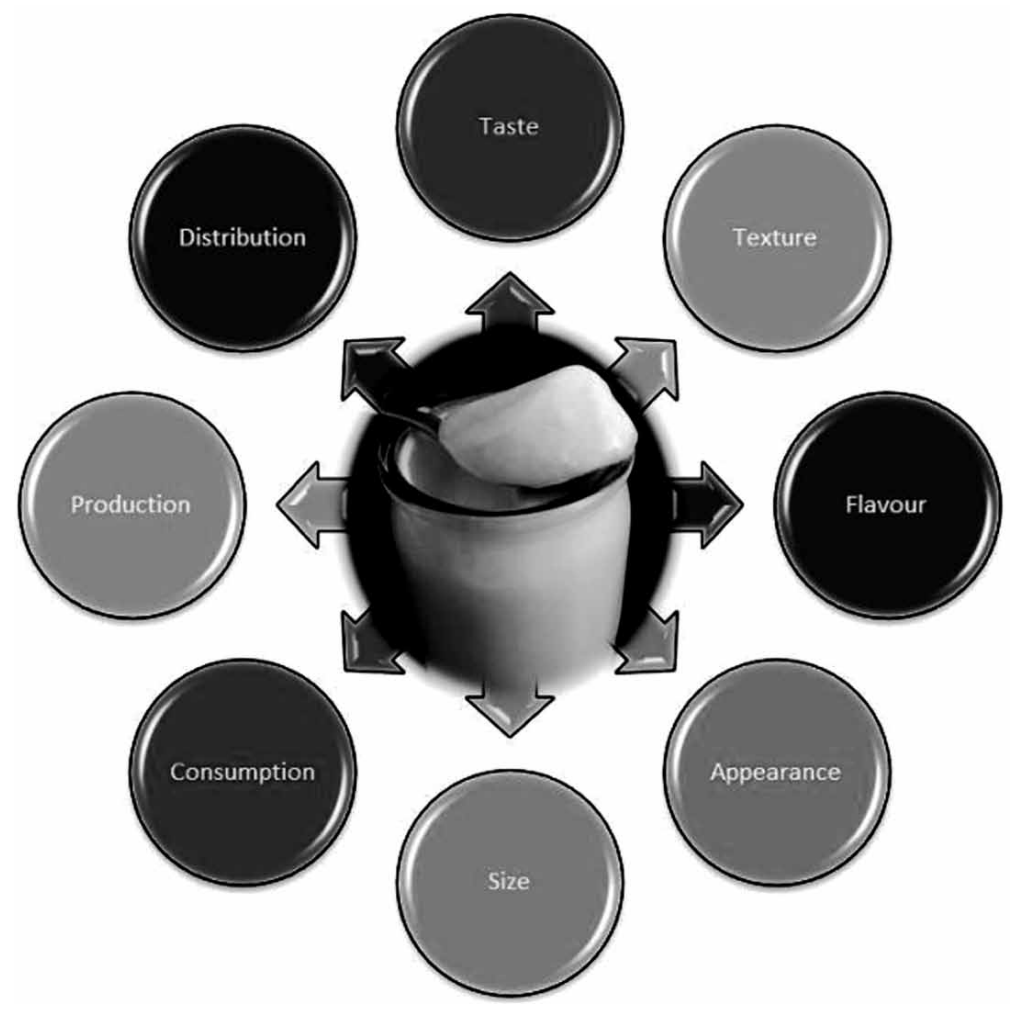

Copyright $(c)$ 2015, IGI Global. Copying or distributing in print or electronic forms without written permission of IGI Global is prohibited. 
employees for new ideas or even, to vote new ideas (developed by a multifunctional team as described above);

3 . It is worthy to mention that there are approx. 56,900,000 blogs on web-sites with topic just only the yoghurt. In these blogs, various characteristic words or indicators can be obtained which are expressed clear consumers' necessities;

4. Finally, the traditional customer-interview questionnaires next to the shops are still useful to obtain information that can be transformed to knowledge.

Furthermore, the voices of retailers and distributors of our products can provide us a lot of pieces of information to prepare both our strategic and tactic actions for a particular business; it is well known as a Market Business Plan and it is integrated within the Master Business Strategy of a firm (Szulanski, 1996). We have to mention that the ability to exploit external knowledge is a critical component of innovative performance (Cohen and Levinthal, 1989).

Thus, the framework presented in Figure 2, allows a direct interaction with consumers and lead users. One of the possible approaches is via the design of the correct questions to crowd source and by obtaining theirresponses. Consumer preferences and opinions were harvested by a mixture of on-line and off-line versions of the questionnaires which focused on product appearance, taste and packaging, Figure 4 and 5, show the questions that have been used to establish the needs of consumers by engaging them in the process. The questionnaires have been designed such that the criteria and priorities shown in Figure 3 could be addressed by the New Product Development Team and later by the Manufacturing Process Development Team. For example the key characteristics for the new yoghurt product that was under development, that have been recognised by the consumers, included as "Light", "Fresh", "Longer Life", "Ecological", "Bio" and even "Lactose Free". Those have

Figure 4. Obtaining consumers' and lead users' inputs
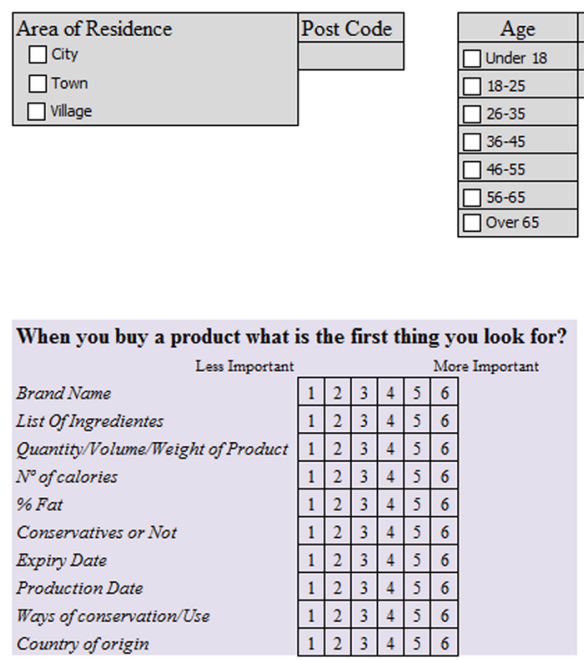

\begin{tabular}{|} 
Are you interesting in products with messages like? \\
\hline Less Important \\
\hline Light & 1 & 2 & 3 & 3 & 4 & 5 & 6 & \\
\hline Fresh & 1 & 2 & 3 & 4 & 5 & 6 & \\
\hline Long Life & 1 & 2 & 3 & 4 & 5 & 6 & \\
\hline Ecological & 1 & 2 & 3 & 4 & 5 & 6 & \\
\hline Bio & 1 & 2 & 3 & 4 & 5 & 6 & \\
\hline Lactose Free & 1 & 2 & 3 & 4 & 5 & 6 & \\
\hline & & & & \multicolumn{5}{|c|}{} \\
\hline
\end{tabular}
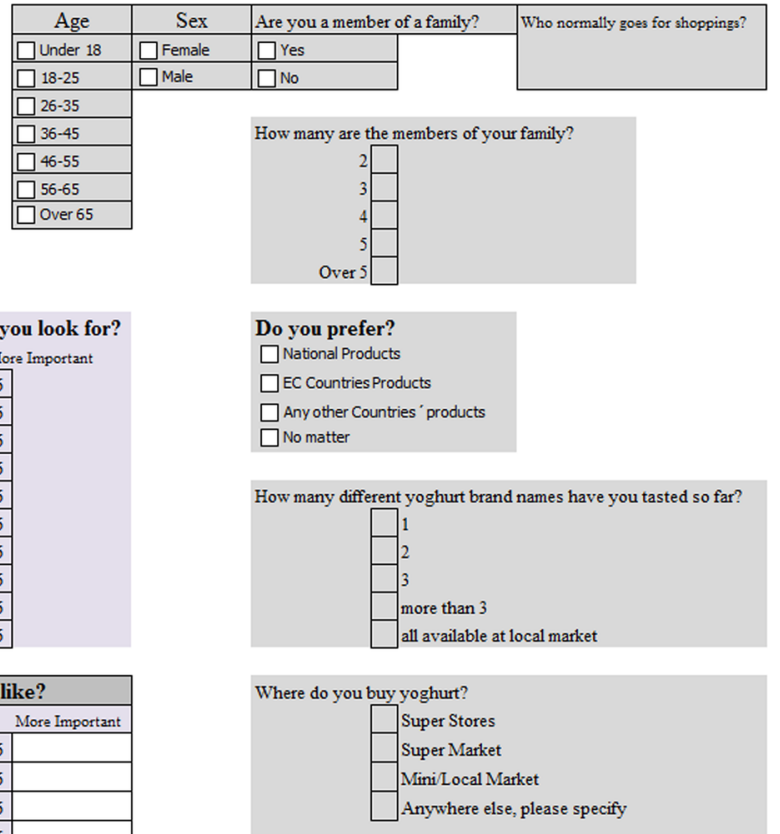
Figure 5. Obtaining consumers' and lead users' inputs

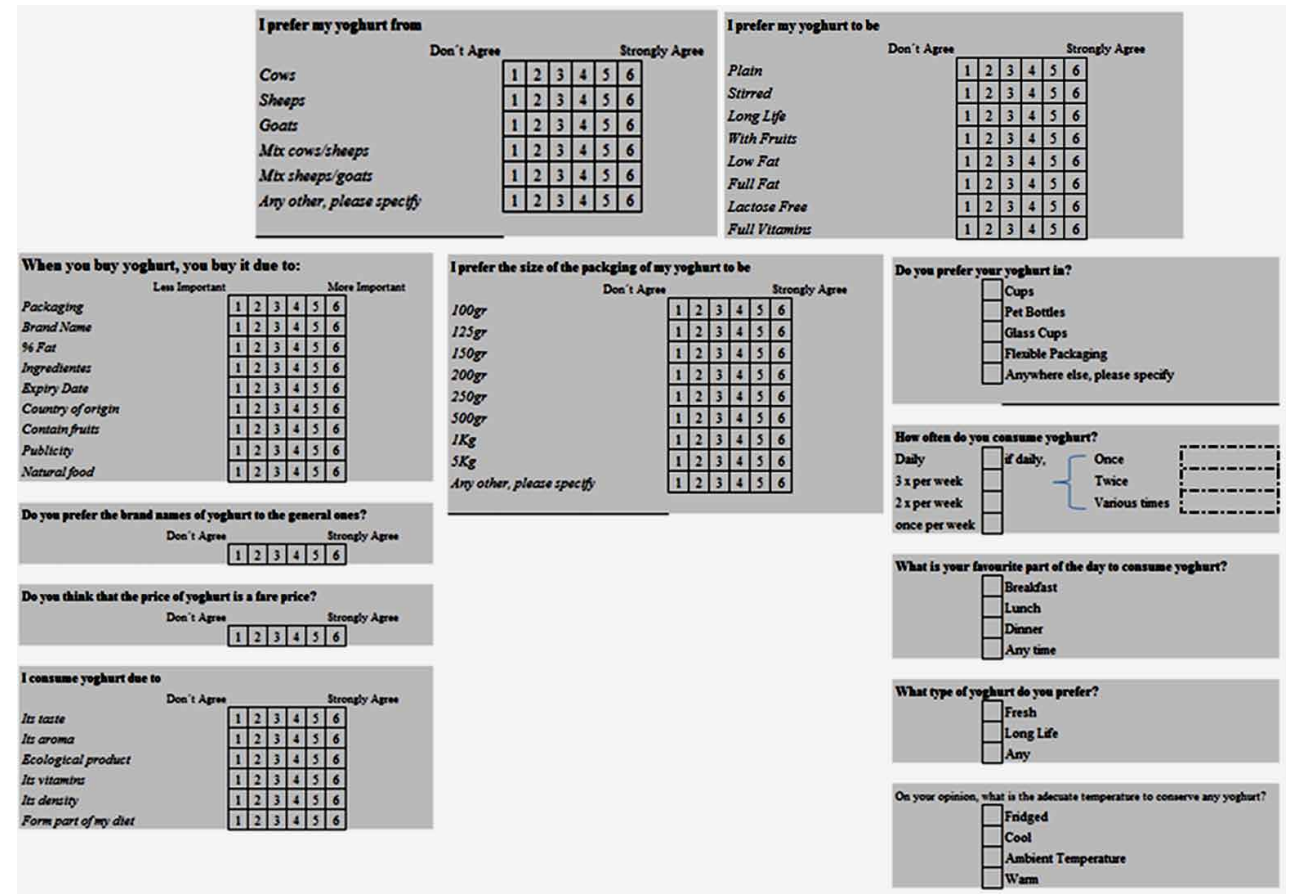

been indicators of high priority to the consumers involved Overseas consumers where engaged in the process by the extensive distribution network of the company, who were then responsible for the collection and sorting of the data.

\subsection{Synthesis to \\ Actionable Formats}

All those previously mentioned inputs represent what consumers value most. The responses are compared against existing practice and the current knowledge of consumer preferences and market segmentation.

On the process and supply sides, knowledge of available processes, manufacturing and distribution capability, ingredient types and availability of them are taken into account. All those inputs and current knowledge are grouped together and mined for new relationships between the data that could reveal new desired product attributes and market segments.
All those considerations lead to the following key product targets:

1. The product should be available in an individual format;

2. The size of the primary packaging of the product should be small;

3. The design of primary packaging should be by that way that consumers always perceive a high quality product;

4. All legal information must be on the primary packaging in different languages.

Table 1 explains the relationship of the above points.

Hence, the outcomes of Table 1 in combination with the inputs obtained from the crowds, leads to a set of basic technological requirements that can be auctioned upon. Figure 6, shows the requirements for a new yoghurt product. 
Table 1. A synthesis table

\begin{tabular}{|l|l|l|}
\hline \multicolumn{1}{|c|}{ Initial Triggers } & \multicolumn{1}{c|}{ How Addressed } & \multicolumn{1}{c|}{ Outcome } \\
\hline 1. Intenational Financial Crisis & $\begin{array}{l}\text { Individual Format and small } \\
\text { packs or group of packs }\end{array}$ & $\begin{array}{l}\text { Small Size (PP) polypropylene material } \\
\text { with (IML) in-mould-labelling }\end{array}$ \\
\hline $\begin{array}{l}\text { 2. The mean number of members of a } \\
\text { family is getting less }\end{array}$ & $\begin{array}{l}\text { Small primarily packaging } \\
\text { and small group of packs }\end{array}$ & Format size: 100gr \& 125gr \\
\hline $\begin{array}{l}\text { 3. The "single" consumers prefer ready- } \\
\text { to-use products in individual formats }\end{array}$ & $\begin{array}{l}\text { Individual format and ease } \\
\text { of use }\end{array}$ & Type of pot: On-the-go with spoon \\
\hline $\begin{array}{l}\text { 4. Consumers of undeveloped countries } \\
\text { cannot afford to buy huge format packs }\end{array}$ & $\begin{array}{l}\text { Individual Format and small } \\
\text { primarily packaging }\end{array}$ & Sell individually or in pack of 4 \\
\hline $\begin{array}{l}\text { 5. The new international labelling } \\
\text { system requirements for the primary } \\
\text { packaging }\end{array}$ & $\begin{array}{l}\text { Legal information on } \\
\text { primarily packaging }\end{array}$ & $\begin{array}{l}\text { The label with legal information } \\
\text { embodied on the pot }\end{array}$ \\
\hline $\begin{array}{l}\text { 6. The necessity for a more flexible } \\
\text { world-wide distribution }\end{array}$ & $\begin{array}{l}\text { Legal information on } \\
\text { primarily packaging in } \\
\text { different languages }\end{array}$ & $\begin{array}{l}\text { 6 main languages to sell all over the } \\
\text { world: EN, SP, FR, AR, CH, AR }\end{array}$ \\
\hline $\begin{array}{l}\text { 7. The demand for more and more } \\
\text { sustainable products without losing } \\
\text { quality }\end{array}$ & $\begin{array}{l}\text { Sustainable type of } \\
\text { packaging and product }\end{array}$ & $\begin{array}{l}\text { PP with IML } \\
\text { Long life product (9 months) } \\
\text { Fridge conservation is not needed }\end{array}$ \\
\hline
\end{tabular}

In the yoghurt case, the design of the primary packaging with all accessory components and characteristics is clearly defined by prototypes, the machinery to process such a kind of packaging and product is also defined by industrial trials and all other aspects such as additional formats, promotional formats, trays, palletizing patterns, etc. that are related to consumers' wants are clearly defined and prototyped.

At this stage, by using the external knowledge of selected and lead machine and materials suppliers and the openness and share information with them in a timely manner (Laursen and Salter, 2006; Garriga et al., 2013) have been proved to provide a big advantage to get to market faster.

Furthermore, it is important to mention that agility is a key component for success as all type of machinery should be selected by having that added performance value in mind. For the yoghurt facilities, the specific characteristics of the manufacturing line are:

1. Well-designed planned capacity of the whole production line;
2. Excellent production scheduling;

3. Automated control of the whole process and production line;

4. Quick change-overs, easy to handle different formats of primary and secondary packaging;

5. Easy to handle changes in the process plant;

6. Flexibility in changing palletising patterns;

7. Rapid, efficient and effective CIP/SIP cleaning procedures;

8. Hygienic design for any component, etc.

All those aspects have been worked with lead selected machine suppliers as their external knowledge can be used for the firm to obtain a better innovation performance and easier conditions of integration of a new system in existing operations (Laursen and Salter, 2006).

\subsection{Integration into Production}

Those requirements are used to drive product development and the design and execution of the supply chain operations. The framework in Figure 2 embodies the tools for the design and operation of a smartmanufacturing network that 


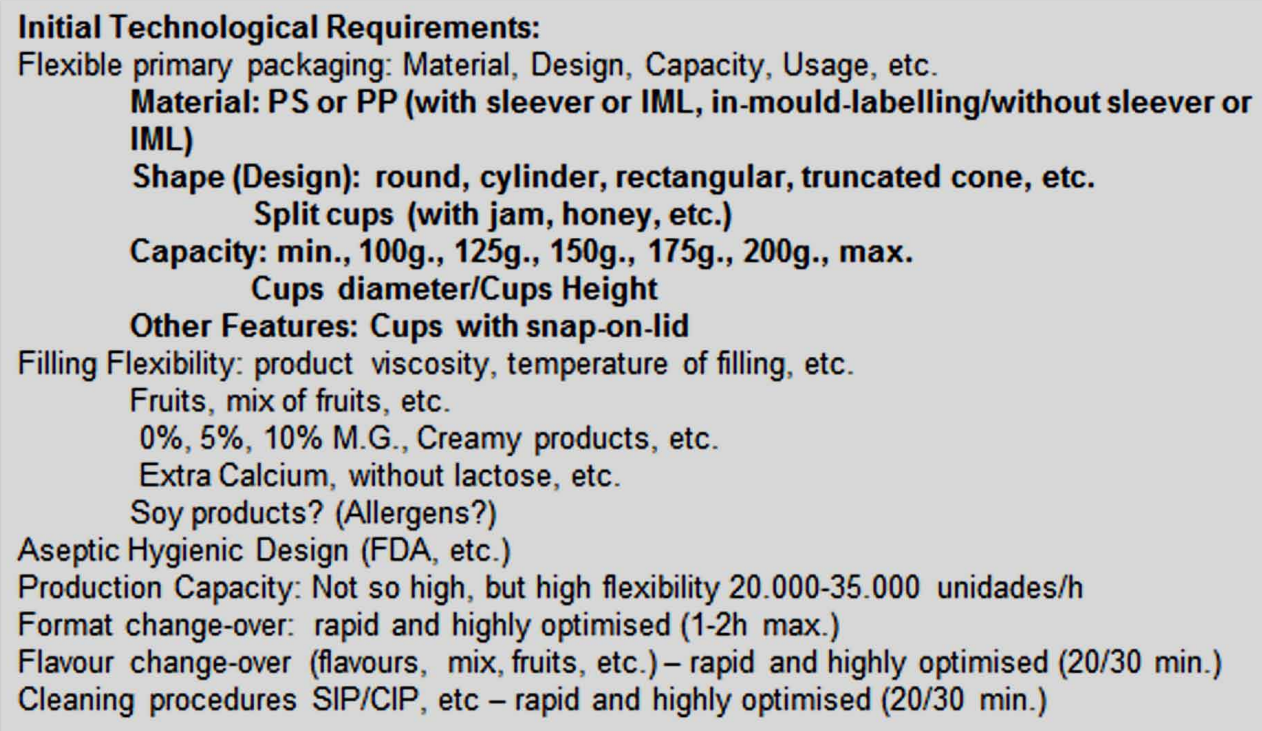

ultimately can drive on-demand manufacturing, where demand allocation and the configuration of the network itself can be determined dynamically, as product requirements and demand evolve. At the design stage, simulation assesses possible manufacturing network configurations and planning algorithms project future execution. The outputs are then set points for manufacturing execution that conventional enterprise resource planning tools can plan against and feeding back actual manufacturing execution progress and exceptions. The next figure shows an example scenario of how a demand of 15,000 cups of yoghurt is handled by our framework.

The customer (C) in Figure 7 has sent an order of 15,000 cups of 100gr., to be received a particular date, with the exact and specific requirements of a yoghurt product. The specific details and information of the order is directly received by the dairy processor and that piece of information is directly shared with the packaging and ingredients partners. By having centralised the formulation of the ordered product, the necessity of ingredients and their deviations are analysed from the reference formulation.
Alerts of clear necessities are generated and immediately they are directly transmitted to the ingredients partners. The information is shared in a similar way with the packaging partners.

It is therefore the common information network that can provide a real on-demand manufacturing and a fast response to the customers' demands. In our case study, such a kind of common information network with suppliers is still under development (due to licenses matters and confidential aspects to be solved). Meanwhile, the internal communication network for any NPD (New Product Development) process has already been developed and it has been in use for almost 2 years.

As a real case study, it is worth mentioning the following obtained results:

1. A better primarily packaging has been designed thanks to the points presented below:

a. The pot appearance and aspect have been improved. The primarily packaging has gained on image due to technology; From Polystyrene (PS) 
Figure 7. Example scenario of a smart on-demand yoghurt manufacturing network

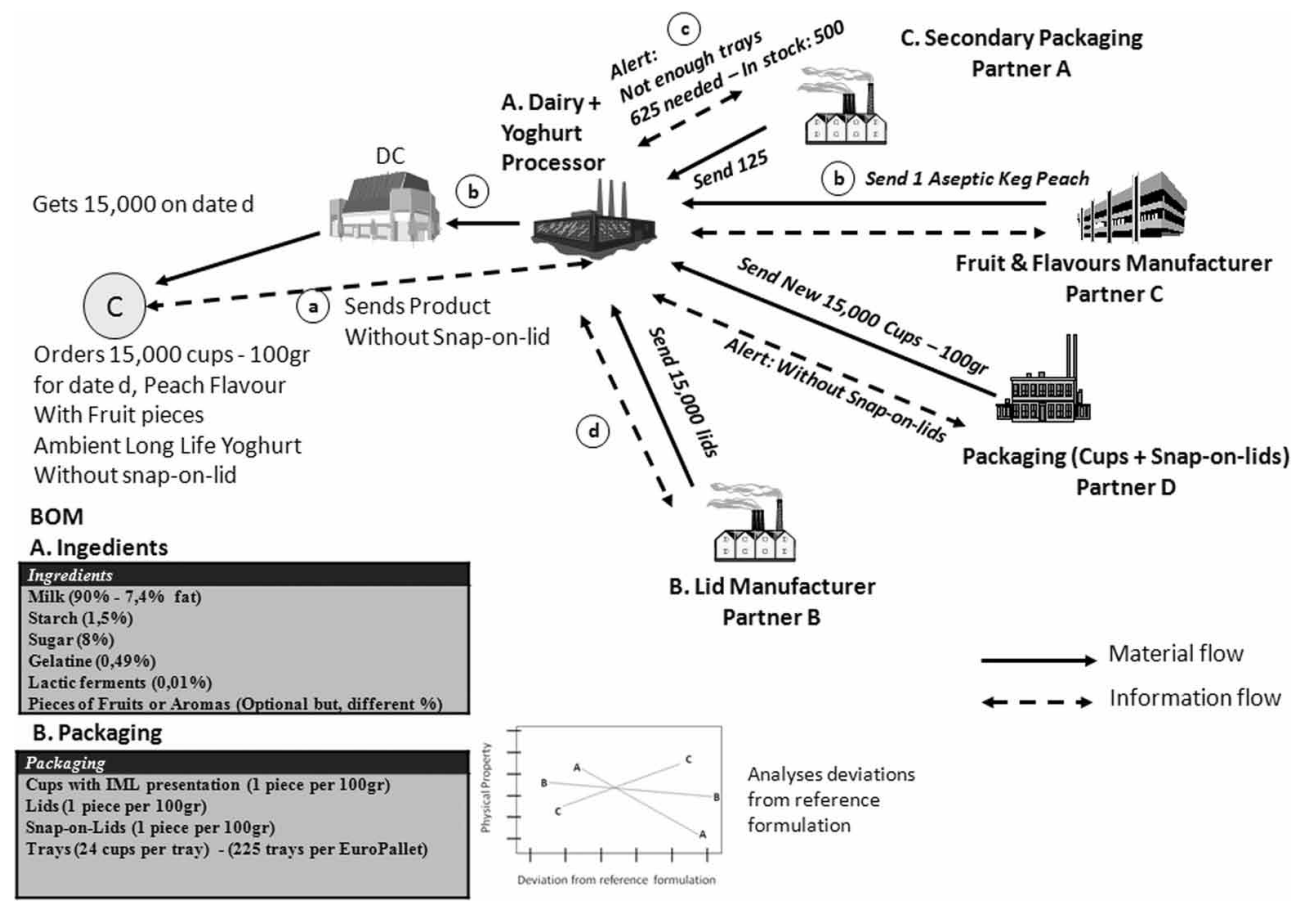

pot to Polypropylene (PP) with IML (in-mould-labelling) pot;

b. The packaging has gained on labelling (quality aspect, premium aspect and at the same time, its label in 6 different languages with all legal information);

c. The packaging has gained on versatility and use as it has been transformed to "on-the-go" pot thanks to its size, shape and spoon that has been attached on its snap-on-lid. The pot is available in two formats: $100 \mathrm{gr}$ and $125 \mathrm{gr}$ and both formats maintain the same diameter at their top so they can be filled by the same filling machine with minor change-overs (approx. 20mins);

2. A better and more versatile product thanks to the advantages of its primarily packaging and the product itself thanks to the next two points:

a. The shelf-life of the product is 9 months; b. The product can be transported and stored at ambient temperature, so it can be sold all over the world, even at places where there is no electricity, transport refrigeration and domestic or commercial refrigerators;

3. So far, sales have been improved by almost $10 \%$, quality cost has been reduced by almost $8-9 \%$ and transport cost has been reduced by $5 \%$.

See Figure 8 for an example of initial and final design.

\section{CONCLUSION AND FUTURE RESEARCH}

In this paper we presented an overview of the framework we proposed for integrating processes with people and design with manufacturing to increase efficiencies in new product development and coordinate with manufactur- 
Figure 8. Initial and final design

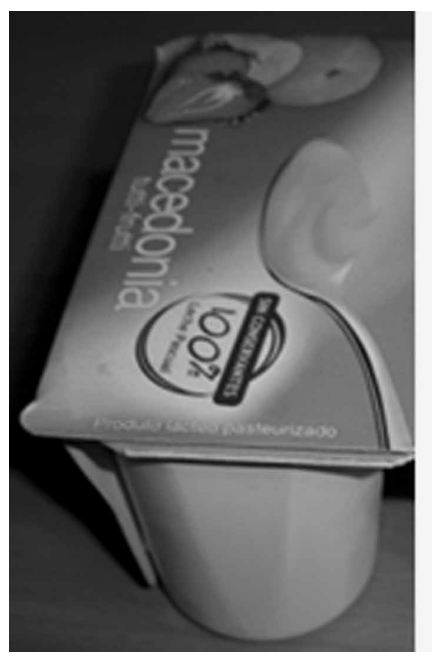

ing. Our framework embodies Open Innovation approaches but not as they are perceived conventionally. Instead of focusing on supplier involvement in product or process innovation, our framework aims at incorporating the end consumer in the new product development loop via appropriately designed processes at the front end of the NPD process. Consumer inputs, priorities and needs, are then translated into an appropriate format to drive the back end processes including packaging design, manufacturing process design ultimately leading to optimised manufacturing and distribution execution.

Agile processes are therefore crucial to the success of such models. To a significant degree, the success of an Agile Manufacturing Unit or even the whole enterprise depends on the application of new technology which supports comprehensively accessing, exchanging, sharing and using information, and speeding up the information and work flow in the product development cycle. In the paper we discussed Open Innovation and the framework we proposed in the context of the development of a new yoghurt product.

Agile materials, capacity planning and control systems are a must. For this reason it is unlikely that over-sophisticated computer- based approaches will succeed over simple approaches. One of the mechanisms to achieve agility is the ability to provide forecasts throughout the supply chain of forthcoming demand without the buffering encountered in current supply chains. This is a significant challenge to the transparency of demand through the supply chain, without the intervention of inventory planners and we think that should be a further study to be realized.

Agility requires not constant changes of plan to satisfy changing customer requirements, but very short lead-times. There is a switch of emphasis here from factory stability, to the customer need. This has a major impact also on production planning and control whereby a product is earmarked for a particular customer fairly early on in the process so that customisation may proceed from that point. This is opposed to the techniques of aggregation connected with MRP systems and is more akin to a make-to-order environment albeit that one product may be very similar to the preceding one. By using simulation and optimisation models and techniques, all those initial risks can be determined and managed more effectively. As part of our research, a further investigation will be taken into that particular area. 


\section{REFERENCES}

Bigliardi, B., \& Galati, F. (2012). Models of adoption of open innovation within the food industry. Trends in Food Science \& Technology, 1(11).

Brown, S. L., \& Eisenhardt, K. M. (1995). Product development: Past research, present findings and future directions. Academy of Management Review, 20(2), 343-378.

Chang, H., Wei, C., \& Lin, R. (2008). A model for selecting product ideas in fuzzy front end. Concurrent Engineering: Research and Applications, 16(2).

Chesbrough, H. (2003). Open innovation: The new imperative for creating \& profiting from technology. Harvard Business School Press.

Chesbrough, H. (2006). Open business models: How to thrive in the new innovation landscape. Harvard Business School Press.

Chesbrough, H., Vanheverbeke, W., \& West, J. (2006). Open innovation: Researching a new paradigm. Oxford University Press.

Christopher, M. (2000). The agile supply chain: Competing in volatile markets. Industrial Marketing Management, 29(1), 37-44. doi:10.1016/S00198501(99)00110-8

Christopher, M. (2005). Logistics \& supply chain management (3rd ed.). Prentice Hall.

Cohen, W. M., \& Levinthal, D. A. (1989). Innovation and learning: The two faces of R\&D. The Economic Journal, 99(397), 569-596. doi:10.2307/2233763

DEFRA, (2009). Food statistics pocket book.

Design Council. (2005). Eleven lessons: Managing design in eleven global brands, The design process. Retrieved from www.designcouncil.org.uk

Dougherty, D. (1992). Interpretive barriers to successful product innovation in large firms. Organization Science, 3(2), 179-202. doi:10.1287/orsc.3.2.179

Garriga, H., Von Krogh, G., \& Spaeth, S. (2013). How constraints and knowledge impact open innovation. Strategic Management Journal, 34(9), 1134-1144. doi:10.1002/smj.2049

Hawkes, C. (2004). Nutritional labels and health claims: The global regulatory environment. World Health Organization. ISBN 9241591714.

Henten, A. (2012). Innovations from the ICT-based service encounter. [Emerald Group Publishing Limited.]. Browse Journals \& Books, 14(2), 42-56.
Hyve. (2011). Co-creation and open innovation in new product development. Retrieved from http:// www.youtube.com/watch? $\mathrm{v}=6 \mathrm{~V} 1 \mathrm{dWH} 4 \mathrm{X} 9 \mathrm{U} 0$

Karnani, A. (2014). Selling to the Poor. The World Financial Review. Retrieved from http://www. worldfinancialreview.com/?p=215 (last accessed 29/05/2014)

Keating, B.A., Carberry, P. S., Bindraban, B.,Asseng, S., Meinke, H., \& Dixon, J. (2010). Eco-efficient Agriculture: Concepts, Challenges and Opportunities. Crop Science, 50(Supplement 1), 109-119. doi:10.2135/cropsci2009.10.0594

Laursen, K., \& Salter, A. (2006). Open for innovation: The role of openness in explaining innovation performance among UK manufacturing firms. Strategic Management Journal, 27(2), 131-150. doi:10.1002/smj.507

Lynn, G. S., Abel, K. D., Valentine, W. S., \& Wright, R. C. (1999). Key Factors in Increasing Speed to Market and Improving New Product Success Rates. Industrial Marketing Management, 28(4), 319-326. doi:10.1016/S0019-8501(98)00008-X

Manalili, N. M., Dorado, M. A., \& Van Otterdijk, R. (2011). Appropriate Food Packaging Solutions for Developing Countries. Study conducted for the International Congress "SAVE FOOD!" at Interpack 2011, Düsseldorf, Germany.

Miranda, F. J., \& Bañegil, T. M. (2002). The effect of new product development techniques on new product success in Spanish firms. Industrial Marketing Management, 31(3), 261-271. doi:10.1016/ S0019-8501(00)00150-4

Monsef, S., Khairuzaman, W., \& Ismail, W. (2012, March). The Impact of Open Innovation in New Product Development Process. International Journal of Fundamental Psychology \& Social Sciences, 2(1), 7-12.

Morcillo, P. (2007). Cultura e Innovación Empresarial. Thomson Editores Spain.

Nielsen Report. (2006). Consumers and ready-to-eat meals: A global AC Nielsen report.

Sarkar, S., \& Costa, A. (2008). Dynamics of open innovation in the food industry. Trends in Food Science \& Technology, 19(11), 574-580. doi:10.1016/j. tifs.2008.09.006

Sawhney, M., \& Prandelli, E. (2000). Communities of creation: Managing distributed innovation in turbulent markets. California Management Review, 42(4), 24-54. doi:10.2307/41166052 
Slack, N., Chambers, S., \& Johnston, R. (2007). Operations management (5th ed.). Prentice Hall.

Szulanski, G. (1996). Exploiting internal stickiness: Impediments to the transfer of best practice. Strategic Management Journal, 17, 27-43.

Tidd, J., Bessant, J., \& Pavitt, K. L. R. (2000). Managing innovation: Integrating technological market and organisational change (2nd ed.). Chichester, UK: Wiley.
Trompenaars, F., \& Hampden, C. (2009). Innovating in a global crisis. Infinite Ideas Limited.

UK Cabinet Office. (2008). Food matters - Towards a strategy for the 21st Century.

Unstats. (n.d.). The world's women 2010: Trends and statistics. Retrieved from http://unstats.un.org/ unsd/demographic/products/Worldswomen/Executive\%20summary.htm

Wild, R. (1992). Production \& Operations Management (4th ed.). Cassell. 